\title{
Relationship between high platelet reactivity on clopidogrel and long-term clinical outcomes after drug-eluting stents implantation (PAINT-DES): a prospective, propensity score-matched cohort study
}

\author{
Xiao-Fei Gao ${ }^{1+}$, Shu Lu ${ }^{2+}$, Zhen Ge ${ }^{3}$, Guang-Feng Zuo ${ }^{3}$, Zhi-Mei Wang ${ }^{1}$, Feng Wang ${ }^{1}$, Xiang-Quan Kong ${ }^{3}$,
} Da-Yang Chai ${ }^{2}$, Shao-Liang Chen ${ }^{1,3}$ and Jun-Jie Zhang ${ }^{1,3^{*}}$ (D)

\begin{abstract}
Background: The relationship between platelet reactivity and long-term clinical outcomes remains controversial. The present prospective study was designed to explore the association between high platelet reactivity (HPR) on clopidogrel and long-term clinical outcomes following implantation of drug eluting stents (DES).

Methods: A total of 1769 consecutive patients assessed by Aggrestar (PL-11) were enrolled at our center from February 2011 to December 2017. The primary end point was major adverse cardiovascular and cerebrovascular events (MACCE), defined as definite or probable stent thrombosis, spontaneous myocardial infarction, all cause death, clinically driven target vessel revascularization (TVR), or ischemic stroke. Bleeding served as the safety endpoint. Propensity score matching (PSM) analysis was performed to adjust for baseline differences in the overall cohort.
\end{abstract}

Results: Finally, 409 patients (23.1\%) were identified with HPR on clopidogrel. At a median follow-up of 4.1 years (interquartile range, 1.8 years), the occurrence of MACCE was significantly higher in HPR on clopidogrel group than normal platelet reactivity (NPR) on clopidogrel group (15.6\% vs. 5.4\%, $p<0.001)$. After PSM, 395 paired patients were matched, and the difference in MACCE between HPR (15.7\%) versus NPR (9.4\%) on clopidogrel groups remained significant $(P<0.001)$, mainly driven by increased all cause death $(5.3 \%$ vs. $1.8 \%, p<0.001)$, and clinically driven TVR (8. $1 \%$ vs. $6.3 \%, p=0.019)$ in the HPR group. The risk of bleeding between two groups was similar.

Conclusions: This prospective study confirms the relationship between HPR on clopidogrel and long-term adverse cardiovascular events after coronary stenting.

Keywords: Platelet function testing, Clopidogrel, High platelet reactivity, Drug eluting stent

\section{Background}

Dual antiplatelet therapy with aspirin and clopidogrel, an adenosine diphosphate (ADP)-receptor inhibitor, is widely prescribed for patients with percutaneous coronary intervention (PCI) to prevent stent thrombosis,

\footnotetext{
* Correspondence: jameszll@163.com

${ }^{+}$Xiao-Fei Gao and Shu Lu contributed equally to this work.

'Department of Cardiology, Nanjing First Hospital, Nanjing Medical

University, No. 68 Changle Road, Nanjing 210006, China

${ }^{3}$ Department of Cardiology, Nanjing Heart Center, Nanjing, China

Full list of author information is available at the end of the article
}

which has a high risk of myocardial infarction (MI) and cardiac death $[1,2]$. However, patients treated with protocolized aspirin and clopidogrel may still develop adverse cardiovascular events, and high platelet reactivity (HPR) on clopidogrel (clopidogrel no-response or clopidogrel resistance) has been thought to play a critical role in their occurrence [3].

In platelet function testing studies $[4,5]$, the rate of HPR on clopidogrel was $4-46 \%$ in patients on conventional dose of clopidogrel. Randomized clinical trials (RCTs) [6-9] failed to show benefit of antiplatelet

(c) The Author(s). 2018 Open Access This article is distributed under the terms of the Creative Commons Attribution 4.0 International License (http://creativecommons.org/licenses/by/4.0/), which permits unrestricted use, distribution, and reproduction in any medium, provided you give appropriate credit to the original author(s) and the source, provide a link to the Creative Commons license, and indicate if changes were made. The Creative Commons Public Domain Dedication waiver (http://creativecommons.org/publicdomain/zero/1.0/) applies to the data made available in this article, unless otherwise stated. 
regimen adjustment according to platelet function testing for coronary stenting, which might partly be due to exclusion of high-risk patients, and randomization performed a few hours after PCI. The current consensus [10] from large observational studies [3, 11-14] is that HPR on clopidogrel is associated with increased short-term risk of cardiac events following drug-eluting stents (DES) implantation. However, there is scarce evidence on the relationship between HPR on clopidogrel and long-term cardiovascular events in PCI patients. Therefore, the present prospective, propensity score-matched (PSM) cohort study explored the long-term impact of HPR on clopidogrel in patients with DES implantation.

\section{Methods}

\section{Study design and population}

The PAINT-DES is a prospective, single-center cohort study designed to assess the association between HPR on clopidogrel and long-term cardiovascular events in patients with DES implantation. From February 2011 to December 2017, a total of 6200 consecutive real-word PCI patients at our center with loading dose of aspirin and clopidogrel were candidates for this study. Finally, 1769 patients with platelet function testing were enrolled in the present study if they met the following inclusion criteria: age $>18$ years, and at least one successful DES implantation. The major exclusion criteria were: patients on ticagrelor or oral anticoagulation (warfarin, dabigatran, rivaroxaban, etc.); platelet count $<10 \times 10^{9} / \mathrm{L}$; acute myocardial infarction $<24 \mathrm{~h}$; suspected intolerance to study drugs; major complication during PCI; and an estimated life expectancy $<12$ months (Additional file 1: Figure S1). Cases missing $>10 \%$ of baseline variables also were excluded. The study protocol and informed consent were reviewed and approved by the Institutional Review Board of Nanjing First Hospital. Written informed consent for participation was obtained from all enrolled patients.

\section{Procedure and medication}

All coronary interventions were performed according to current standards. Use of coronary imaging tools, type of DES, low molecular weight heparin, glycoprotein IIb/ IIIa inhibitors, and intra-aortic balloon pump counterpulsation were at operator's discretion. Patients not on aspirin $100 \mathrm{mg}$ daily for more than 7 days were loaded with $300 \mathrm{mg}$ at least $6 \mathrm{~h}$ prior to index procedure. A loading dose of clopidogrel of $300 \mathrm{mg}$ or $600 \mathrm{mg}$ was prescribed at least $6 \mathrm{~h}$ before the procedure, followed by a daily maintenance dose of $75 \mathrm{mg}$. Total creatine kinase (CK), CK-myocardial-band isoenzyme (MB), and troponin $\mathrm{T} / \mathrm{I}$ were dynamically measured before the procedure and until $72 \mathrm{~h}$ post-procedure. After the procedure, all patients were prescribed aspirin $100 \mathrm{mg}$ daily indefinitely and clopidogrel $75 \mathrm{mg}$ daily for at least 12 months.

\section{Platelet function testing}

Platelet function testing with Aggrestar (PL-11) analyzer (SINNOWA Co., Nanjing, China) was performed before heparin or antithrombotic agent administration during the index procedure in the cardiac catheterization lab. Blood samples were stored at room temperature and tested within $2 \mathrm{~h}$ after collection. Information on the Aggrestar analyzer has been provided in detail before $[12,15]$. Briefly, platelet function was tested using sequentially platelet counting method, with automatically and sequentially counting platelet numbers in the citrated whole blood sample before and after adding agonists at fixed time intervals. Aggrestar analyzer provides more stable and accurate platelet maximum aggregation ratio (MAR\%) than standardized test method. HPR on clopidogrel was defined as $\mathrm{MAR} \% \geq 55 \%$ according to a previous study [12]. It was not recommended to adjust antiplatelet strategy based on the results of platelet function testing.

\section{Endpoints and definitions}

The primary endpoint was rate of major adverse cardiovascular and cerebrovascular events (MACCE), defined as definite or probable stent thrombosis, spontaneous MI, all cause death, clinically driven target vessel revascularization (TVR), or ischemic stroke. The secondary endpoints included stent thrombosis, cardiac death, clinically driven target lesion revascularization (TLR), and individual components of the primary endpoint. Spontaneous MI was diagnosed based on Third Universal Definition of Myocardial Infarction [16]. Cardiac death was defined as any death without a clear non-cardiac cause. Clinically driven TLR or TVR was defined as angina or ischemia referable to the target lesion or target vessel requiring repeated PCI or bypass surgery. Ischemic stroke was defined as neurological deficit of cerebrovascular cause according to the related symptoms and physical examination and brain imaging. Bleeding served as the safety endpoint, defined in accordance to the Bleeding Academic Research Consortium (BARC) classification [17]. Stent thrombosis was defined based on the Academic Research Consortium (ARC) classification [18]. Lesion specificities were defined based on American Heart Association/American College of Cardiology criteria [19]. Complex coronary lesions in this study were defined as one of the following: multi-vessel lesions, moderate to severe calcification, chronic total occlusion, coronary bifurcations treated with two-stent techniques, and unprotected left main lesions. 


\section{Follow up}

Clinical follow-up was conducted with visits (preferred) or telephone contact at $1,6,12$ months, and yearly thereafter. Angiographic follow-up was scheduled for all patients at 13 months after PCI, unless clinically indicated earlier. An independent committee that was blinded to the study assessed all adverse clinical events.

\section{Statistical analysis}

Continuous baseline variables are expressed as means \pm standard deviation (SD) or median (interquartile range) and were compared using Students' $t$-test for normal data and Wilcoxon rank sum scores for non-normally distributed data. Categorical variables are expressed as counts and percentages and were compared by Chi-square test or Fisher's exact test. Time-to-first event curves between two groups were generated by Kaplan-Meier analysis and compared by a log-rank test. For significant differences $(p<0.10)$ in baseline clinical characteristics (age, male, body mass index [BMI], hypertension, hyperlipidemia, current smoker, prior stroke, prior MI, and prior $\mathrm{PCI}$ ), and procedural characteristics (chronic total occlusion, and complete revascularization) between two groups, propensity score matching at a ratio of 1:1 was performed to minimize any selection bias using logistic regression according to the nearest rule, with matching tolerance of 0.01 . Potential interactions between the subgroups and platelet reactivity were examined for the primary outcome. Multivariable Cox proportional hazards forward stepwise regression was performed to determine independent predictors of the primary endpoint with purposeful selection of covariates. The variables showing possible statistical significance $(P<0.10)$ in univariable model and those judged to be of clinical importance from previous studies (age, male, body mass index, hypertension, diabetes, current smoker, complex lesions, stent number, intravascular ultrasound used, and complete revascularization) were entered into the Cox multivariable model. All statistical tests were two-sided, and a $p$-value of $<0.05$ was considered statistically significant. All statistical analyses were performed with SPSS version 24.0 (SPSS Institute Inc., Chicago, Illinois, USA).

\section{Results}

\section{Baseline clinical characteristics}

Of 1769 patients with DES implantation, 409 (23.1\%) were in the HPR on clopidogrel group, and the remainder was in the normal platelet reactivity (NPR) on clopidogrel group. The baseline clinical characteristics are summarized in Table 1. Notably, patients in the HPR on clopidogrel group were older $(66.9 \pm 10.2)$, and with higher BMI $\left(25.1 \pm 3.6 \mathrm{~kg} / \mathrm{mm}^{2}\right)$, and more frequent hypertension (76.0\%), hyperlipidemia (49.9\%), and prior stroke $(3.7 \%)$ when compared with the NPR on clopidogrel group $(64.6 \pm 10.2, p<0.001 ; 24.6 \pm 2.9 \mathrm{~kg} /$ $\mathrm{mm} 2, \quad p=0.003 ; \quad 69.8 \%, \quad p=0.014 ; \quad 38.3 \%, \quad p<0.001$; $1.3 \%, p=0.005$, respectively). They also were less often men $(70.7 \%$ versus $75.6 \%, p=0.045)$. All the other baseline variables were similarly distributed.

\section{Lesion and procedural characteristics}

Table 2 shows that patients in the HPR on clopidogrel group had more frequent chronic total occlusion (15.4\%) compared with the NPR on clopidogrel group (10.0\%, $p=0.003)$. Moreover, there was a numerically lower rate of complete revascularization for all diseased coronary segments (defined as $\geq 2.5 \mathrm{~mm}$ in diameter by visual estimation) in the HPR on clopidogrel group than that in the NPR on clopidogrel group $(59.6 \%$ vs. $64.8 \%, p=0.054)$. All the other angiographic and procedural characteristics were comparable between two groups.

\section{Unadjusted clinical outcomes}

Clinical follow-up was available in $94.7 \%$ of all patients, and angiographic follow-up was conducted in $70.1 \%$ of patients. Unadjusted clinical outcomes are listed in Table 3. After a median follow-up of 4.1 years (interquartile range, 1.8 years), the incidence of definite and probable stent thrombosis, all cause death, clinically driven TVR, and ischemic stroke in the HPR on clopidogrel group was $1.5,5.1,7.8$, and $2.2 \%$, respectively, which was significantly higher than $0.3 \%(p=0.003), 1.3 \%(p<$ $0.001), 3.2 \%(p<0.001)$, and $0.5 \%(\mathrm{p}<0.001)$, respectively, in the NPR on clopidogrel group, resulting in more frequent MACCE in the HPR on clopidogrel group (15.6\% vs. $5.4 \%, p<0.001)$. The occurrence of bleeding (BARC classification $\geq 2$ ) was $2.9 \%$ in the HPR on clopidogrel group, which was comparable with $2.6 \%$ in the NPR on clopidogrel group $(p=0.754)$.

\section{Propensity score matched analysis}

After PSM, 395 pairs of patients were matched. The baseline characteristics became comparable between two groups (Tables 1 and 2). There was still a significant difference in MACCE between the NPR on clopidogrel group and the HPR on clopidogrel group $(9.4 \%$ vs. $15.7 \%, p<0.001$; Table 3, Fig. 1), mainly driven by increased all cause death $(1.8 \%$ vs. $5.3 \%, p<0.001)$, and clinically driven TVR $(6.3 \%$ vs. $8.1 \%, p=0.019)$ in the latter group. The risk of bleeding (BARC classification $\geq 2$ ) between these two groups remained similar. There were no significant interactions between any of the subgroups and platelet reactivity for MACCE (Fig. 2). In Cox regression multivariable analysis, diabetes (hazard ratio [HR]: 1.566, 95\% confidence interval [CI]: 1.028-2.385, $p=0.037$ ), HPR on clopidogrel (HR: 2.146, 95\% CI: $1.387-3.320, p=0.001)$, and complex coronary lesions (HR: 2.510, 95\% CI: 1.522-4.140, $p<0.001$ ) were 
Table 1 Baseline clinical characteristics

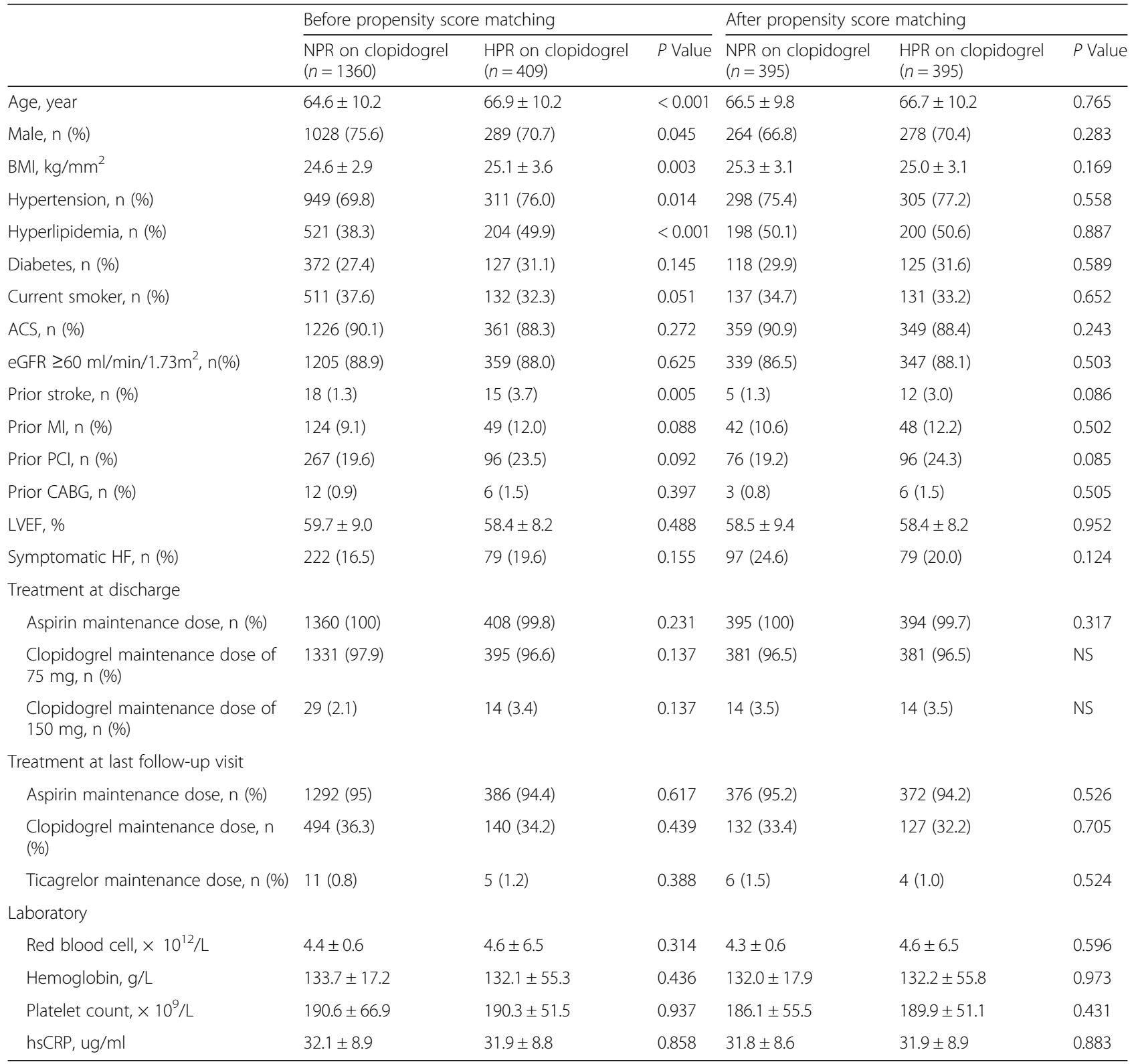

NPR normal platelet reactivity, HPR high platelet reactivity, $B M I$ body mass index, ACS acute coronary syndrome, eGFR estimated glomerular filtration rate, $M I$ myocardial infarction, $P C l$ percutaneous coronary intervention, $C A B G$ coronary artery bypass grafting, $L V E F$ left ventricular ejection fraction, $H F$ heart failure, $h S C R P$ high sensitivity $C$ reactive protein

independent predictors of MACCE at a median follow-up of 4.1 years.

\section{Discussion}

The present prospective, propensity score-matched cohort study for the first time evaluated the relationship between HPR on clopidogrel and long-term outcomes following DES implantation. The major findings were: 1) $23.1 \%$ of patients with DES implantation were identified with HPR on clopidogrel despite having received loading dose of clopidogrel; 2) HPR on clopidogrel was associated with dramatic increment in unadjusted and adjusted long-term MACCE, mainly driven by increased all cause death and clinically driven TVR; and 3) there was no significant association between platelet reactivity and unadjusted and adjusted risk of bleeding.

Antiplatelet agents, aspirin and clopidogrel, have a critical role in the treatment of coronary heart disease, ischemic stroke and peripheral artery disease. However, stented patients suffer from recurrent thrombotic events despite being on regular aspirin and clopidogrel, which might be due to HPR on clopidogrel. Several factors [20-22] might underlie HPR on clopidogrel including patient noncompliance, intestinal absorption (ABCB1 
Table 2 Angiographic and procedural characteristics

\begin{tabular}{|c|c|c|c|c|c|c|}
\hline & \multicolumn{3}{|c|}{ Before propensity score matching $^{a}$} & \multicolumn{3}{|c|}{ After propensity score matching } \\
\hline & $\begin{array}{l}\text { NPR on clopidogrel } \\
(n=1360)\end{array}$ & $\begin{array}{l}\text { HPR on clopidogrel } \\
(n=409)\end{array}$ & $P$ Value & $\begin{array}{l}\text { NPR on clopidogrel } \\
(n=395)\end{array}$ & $\begin{array}{l}\text { HPR on clopidogrel } \\
(n=395)\end{array}$ & $P$ Value \\
\hline Radial access, n (\%) & $1249(92.9)$ & $372(92.1)$ & 0.596 & $355(89.9)$ & $367(92.9)$ & 0.128 \\
\hline Multi-vessel disease, n (\%) & $605(46.4)$ & $200(49.5)$ & 0.280 & $188(50.4)$ & $196(51.0)$ & 0.860 \\
\hline Bifurcation lesion, n (\%) & $410(30.5)$ & $135(33.4)$ & 0.268 & $129(32.7)$ & $133(33.7)$ & 0.762 \\
\hline Chronic total occlusion, n (\%) & $133(10.0)$ & $63(15.4)$ & 0.003 & $64(16.2)$ & $62(15.7)$ & 0.846 \\
\hline Unprotected Left main lesions, n (\%) & $146(10.9)$ & $46(11.4)$ & 0.765 & $51(12.9)$ & $45(11.4)$ & 0.514 \\
\hline Second-generation DES used, n (\%) & $1360(100)$ & $409(100)$ & NS & $395(100)$ & $395(100)$ & NS \\
\hline IABP used, n (\%) & $23(1.8)$ & $6(1.6)$ & 0.753 & $13(3.5)$ & $6(1.6)$ & 0.108 \\
\hline IVUS used, n (\%) & $291(22.9)$ & $100(26.1)$ & 0.189 & $79(21.2)$ & $97(26.2)$ & 0.106 \\
\hline Stent number & $1.9 \pm 1.1$ & $1.9 \pm 1.1$ & 0.328 & $1.9 \pm 1.1$ & $1.9 \pm 1.1$ & 0.946 \\
\hline Mean stent diameter, $\mathrm{mm}$ & $3.0 \pm 0.7$ & $2.9 \pm 0.7$ & 0.770 & $3.0 \pm 0.6$ & $2.9 \pm 0.7$ & 0.166 \\
\hline Stent length, mm & $49.1 \pm 31.2$ & $51.0 \pm 30.4$ & 0.299 & $49.6 \pm 31.1$ & $50.6 \pm 30.2$ & 0.650 \\
\hline Complete revascularization, n (\%) & $852(64.8)$ & $240(59.6)$ & 0.054 & $252(63.8)$ & $237(60.0)$ & 0.272 \\
\hline Final TIMI grade 3, n (\%) & $1301(98.3)$ & $393(97.5)$ & 0.339 & $387(98.5)$ & $384(97.5)$ & 0.315 \\
\hline
\end{tabular}

${ }^{a}$ There is some data loss in dozens of patients

NPR normal platelet reactivity, HPR high platelet reactivity, DES drug-eluting stent, IABP intra-aortic balloon pump, IVUS intravascular ultrasound, TIMI thrombolysis in myocardial infarction

gene polymorphism), polymorphisms in CYP2C19, drug-drug interactions (e.g. omeprazole, $\beta$-Blockers [23]), and other clinical factors (age, BMI, diabetes, chronic renal insufficiency, heart failure). More potent ADP-receptor inhibitors, such as ticagrelor and prasugrel, were expected to overcome HPR on clopidogrel because they showed better clinical outcomes than clopidogrel in patients with acute coronary syndrome (ACS) [24, 25]. However, ticagrelor and prasugrel were associated with higher risk of major bleeding [24-26].
Furthermore, recent studies [27, 28] demonstrated that clopidogrel was superior to ticagrelor to prevent bleeding complications without increased risk of ischemic events in low-to-moderate risk of ACS, especially among those treated with newer-generation DES. Overall, clopidogrel, with low cost and low bleeding risk, is still widely used in clinical practice, and platelet reactivity is worth exploring further.

The optimal method for platelet function testing is still a key and controversial issue. Although various methods

Table 3 Clinical outcomes

\begin{tabular}{|c|c|c|c|c|c|c|}
\hline & \multicolumn{3}{|c|}{ Before propensity score matching } & \multicolumn{3}{|c|}{ After propensity score matching } \\
\hline & $\begin{array}{l}\text { NPR on clopidogrel } \\
(n=1360)\end{array}$ & $\begin{array}{l}\text { HPR on clopidogrel } \\
(n=409)\end{array}$ & $P$ Value & $\begin{array}{l}\text { NPR on clopidogrel } \\
(n=395)\end{array}$ & $\begin{array}{l}\text { HPR on clopidogrel } \\
(n=395)\end{array}$ & $P$ Value \\
\hline Stent thrombosis & $7(0.5)$ & $13(3.2)$ & $<0.001$ & $3(0.8)$ & $13(3.3)$ & 0.003 \\
\hline Definite/ probable Stent thrombosis & $4(0.3)$ & $6(1.5)$ & 0.003 & $2(0.5)$ & $6(1.5)$ & 0.110 \\
\hline All cause death & $18(1.3)$ & $21(5.1)$ & $<0.001$ & $7(1.8)$ & $21(5.3)$ & $<0.001$ \\
\hline Cardiac death & $6(0.4)$ & $10(2.4)$ & 0.001 & $2(0.5)$ & $10(2.5)$ & 0.004 \\
\hline $\mathrm{Ml}$ & $12(0.9)$ & $7(1.7)$ & 0.085 & $6(1.5)$ & $7(1.8)$ & 0.526 \\
\hline STEMI & $4(0.3)$ & $5(1.2)$ & 0.015 & $2(0.5)$ & $5(1.3)$ & 0.215 \\
\hline NSTEMI & $10(0.7)$ & $3(0.7)$ & NS & $5(1.3)$ & $3(0.8)$ & 0.734 \\
\hline Clinically driven TLR & $40(2.9)$ & $26(6.4)$ & $<0.001$ & $24(6.1)$ & $26(6.6)$ & 0.111 \\
\hline Clinically driven TVR & $43(3.2)$ & $32(7.8)$ & $<0.001$ & $25(6.3)$ & $32(8.1)$ & 0.019 \\
\hline Ischemic stroke & $7(0.5)$ & $9(2.2)$ & $<0.001$ & $4(1.0)$ & $7(1.8)$ & 0.093 \\
\hline Bleeding (BARC $\geq 2$ ) & $36(2.6)$ & $12(2.9)$ & 0.754 & $11(2.8)$ & $11(2.8)$ & NS \\
\hline MACCE & $74(5.4)$ & $64(15.6)$ & $<0.001$ & $37(9.4)$ & $62(15.7)$ & $<0.001$ \\
\hline
\end{tabular}

Data are number of events (Kaplan-Meier estimated event rate), compared by the log-rank test

$N P R$ normal platelet reactivity, HPR high platelet reactivity, $M I$ myocardial infarction, TLR target lesion revascularization, TVR target vessel revascularization, MACCE major adverse cardiovascular and cerebrovascular events 


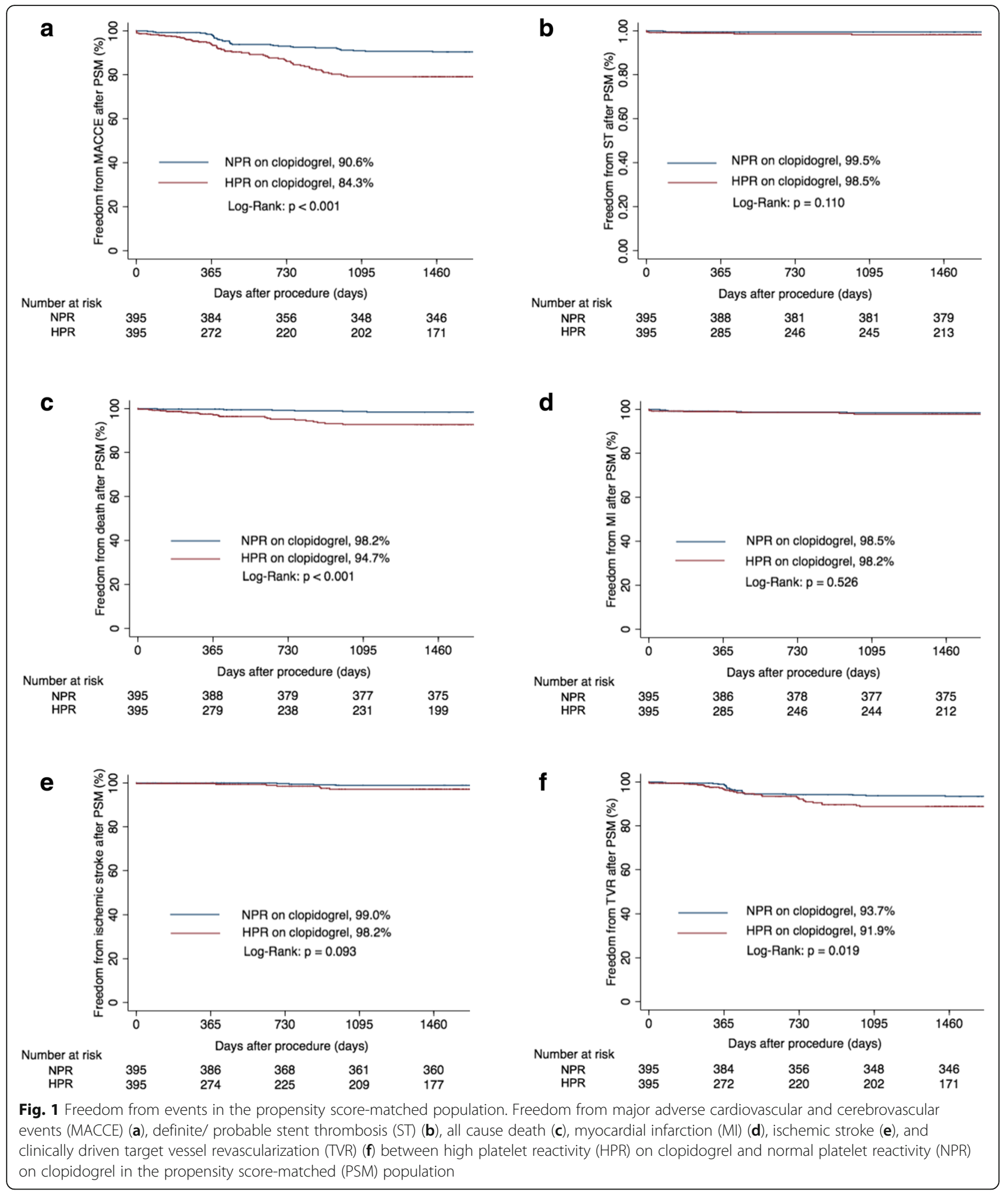

have been developed, their results correlate poorly with each other $[29,30]$. Light transmittance aggregation (LTA) is considered the gold standard, but it is time and labor consuming. VerifyNow system has been widely used in clinical trials, but it is very expensive and nonflexible [31, 32]. As described in the methods section, Aggrestar analyzer provides more stable and accurate platelet numbers, with good correlation with VerifyNow [15], which renders it a reliable alternative for platelet function testing. 


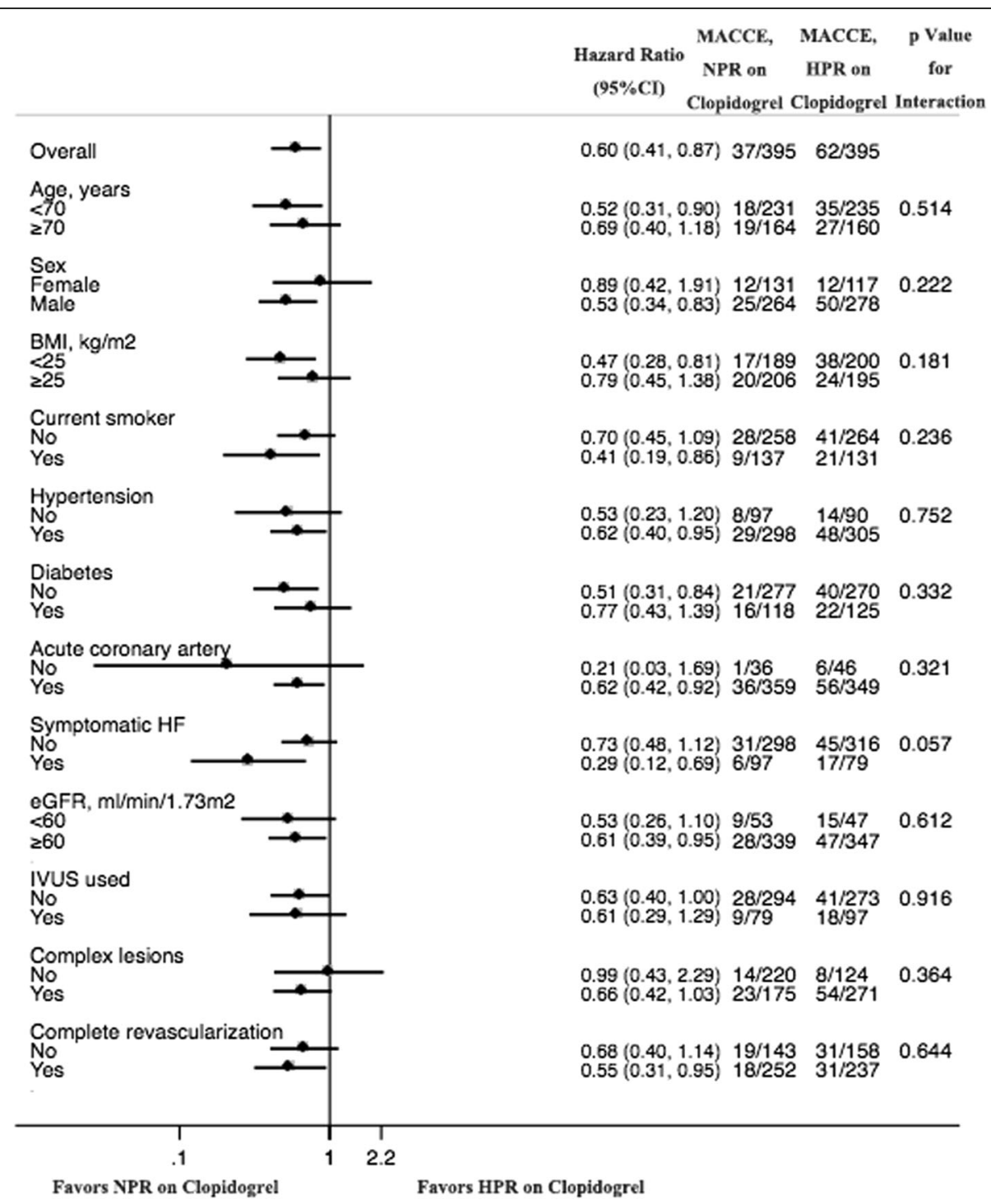

Fig. 2 Subgroup analysis. The increment in major adverse cardiovascular and cerebrovascular events (MACCE) with high platelet reactivity (HPR) on clopidogrel compared with normal platelet reactivity (NPR) on clopidogrel was consistent across pre-specified subgroups. BMI: body mass index; HF: heart failure; eGFR: estimated glomerular filtration rate; IVUS: intravascular ultrasound

Individualized treatment based on platelet function testing was expected to inform choice of more suitable antiplatelet agents and dosage for stenting patients, balancing the risk of ischemia and bleeding. In line with our previous study [12], HPR on clopidogrel was associated with increased risk for stent thrombosis in a prospective multicenter study [14]. The present prospective study with propensity-matched population is the first to confirm the relationship between HPR on clopidogrel and long-term thrombotic events in patients with DES implantation. In contrast to these findings, ARCTIC study (Bedside Monitoring to Adjust Antiplatelet Therapy for Coronary Stenting), including 2440 patients scheduled for coronary stenting, showed no significant improvements in clinical outcomes with platelet function testing and treatment adjustment for coronary stenting [7]. The latter difference might be due to the higher proportion of patients at higher risk in our study, with higher frequency of diabetes, ACS, prior MI, prior $\mathrm{PCI}$, symptomatic heart failure, and complex coronary lesions. However, TROPICAL-ACS trial (The Testing Responsiveness To Platelet Inhibition On Chronic Antiplatelet Treatment For ACS) demonstrated that platelet function testing guided de-escalation of antiplatelet treatment (from prasugrel to clopidogrel) was non-inferior to standard treatment with prasugrel at 1 year after PCI, providing important evidence for ACS patients with coronary stenting in whom early de-escalation is considered as an alternative strategy [33]. Notably, the recent CREATIVE trial [34] (Clopidogrel Response 
Evaluation and AnTi-platelet InterVEntion in High Thrombotic Risk PCI Patients) also showed that intensified antiplatelet strategies with adjunctive use of cilostazol significantly improved clinical outcomes without increasing the risk of major bleeding in patients with HPR on clopidogrel. Consequently, the relationship between clopidogrel hyporesponsiveness and thrombotic events has been probably established, especially in high-risk patients, and a well-designed large-scale RCT with optimal testing method is waarranted to evaluate the real benefit of platelet function testing.

Several questions remain unanswered. First, previous studies [12, 35] showed that HPR on aspirin was also associated with incremental thrombotic events after DES implantation. However, mounting evidence [36-38] supports that HPR on aspirin is either a very rare phenomenon or does not exist, and might due to patient noncompliance, delayed and reduced drug absorption of enteric coating, or drug-drug interactions (e.g. ibuprofen). Second, it was reported [3] that platelet function testing predicts bleeding in patients with bypass surgery. Nevertheless, other studies [12,39] failed to show that platelet function testing reliably predicted future bleeding risk in stenting patients, in line with the present study, which might be due to the low bleeding risk of clopidogrel and coronary intervention. Therefore, the value of platelet function testing in PCI patients should be explored in further studies. Our ongoing PL-PLATELET (Ticagrelor Versus High-dose Clopidogrel in Patients With High Platelet Reactivity on Clopidogrel After PCI, NCT03078465) trial may offer further insight into the effect of platelet function testing on PCI patients.

Our study has several limitations. First, we did not assess the effect of platelet function testing guided therapy adjustment on cardiac events. Second, platelet function testing was performed at index procedure, and enrolled patients did not undergo repeated testing at later time periods. Third, Aggrestar, not VerifyNow, was used in this study due to the high cost of VerifyNow; however, Aggrestar has been shown to correlate well with VerifyNow [15]. Fourth, the study median follow-up of 4.1 years with interquartile range of 1.8 years (skewed distribution) indicates that more patients were enrolled at the early stage of this study, but the duration of follow-up was similar between two groups. Additionally, it was a real-world cohort study, and some patients changed the antiplatelet drugs themselves, although no differences were found between two groups.

\section{Conclusion}

This prospective, propensity score-matched cohort study showed that HPR on clopidogrel was associated with incremental long-term risk of MACCE after DES implantation, mainly driven by increased all cause death and clinically driven TVR. The present study suggests potential benefits for platelet function testing, and a well-designed RCT with optimal testing method is needed to further address the real advantages of platelet function testing.

\section{Additional file}

Additional file 1: Figure S1. Flowchart of study design. PCl:

percutaneous coronary intervention; MAR: maximal aggregation ratio; ADP: adenosine diphosphate. (TIFF $110 \mathrm{~kb}$ )

\begin{abstract}
Abbreviations
ACS: Acute coronary syndrome; ADP: Adenosine diphosphate; BMI: Body mass index; CABG: Coronary artery bypass grafting; DES: Drug-eluting stent; eGFR: Estimated glomerular filtration rate; HF: Heart failure; HPR: High platelet reactivity; hsCRP: High sensitivity $C$ reactive protein; IABP: Intra-aortic balloon pump; IVUS: Intravascular ultrasound; LTA: Light transmittance aggregation; LVEF: Left ventricular ejection fraction; MACCE: Major adverse cardiovascular and cerebrovascular events; MAR: Maximal aggregation ratio; MI: Myocardial infarction; NPR: Normal platelet reactivity; PCl: Percutaneous coronary intervention; PSM: Propensity score matching; RCT: Randomized clinical trial; TIMl: Thrombolysis in myocardial infarction; TLR: Target lesion revascularization; TVR: Target vessel revascularization
\end{abstract}

\section{Acknowledgements}

We deeply appreciate Ms. Hai-Mei Xu, Ms. Jing Kan, and Ms. Ling Lin for remote monitoring and data collection throughout the study.

\section{Funding}

The present study was supported by National Science Foundation of China (NSFC 81770342), Nanjing Health and Family Planning Commission (YKK16124), Nanjing Health Youth Talent Training project (QRX17017), and Nanjing Municipal Commission of Science \& Technology (201715026).

\section{Availability of data and materials}

The raw data supporting the results and conclusions of the present study will be available from the corresponding author on reasonable request.

\section{Authors' contributions}

ZJJ designed the statistical analysis, lead the interpretation of research findings, and revised the manuscript. GXF and LS participated in design, data collection, dataset generation, statistical analysis, and drafting of the manuscript. GZ, ZGF, WZM, WF, KXQ, CDY, and CSL participated in the conception and design and data collection. All of the authors read and approved the final manuscript.

\section{Ethics approval and consent to participate}

The study was approved by the institutional ethics committee of Nanjing First Hospital, and was carried out in accordance with the guidelines of the Declaration of Helsinki. Written informed consent was formally obtained from all participants.

\section{Competing interests}

The authors declare that they have no competing interests.

\section{Publisher's Note}

Springer Nature remains neutral with regard to jurisdictional claims in published maps and institutional affiliations.

\section{Author details}

${ }^{1}$ Department of Cardiology, Nanjing First Hospital, Nanjing Medical University, No. 68 Changle Road, Nanjing 210006, China. ${ }^{2}$ Department of Cardiology, The First People's Hospital of Taicang, Suzhou, China.

${ }^{3}$ Department of Cardiology, Nanjing Heart Center, Nanjing, China. 


\section{Received: 12 March 2018 Accepted: 18 May 2018}

\section{Published online: 24 May 2018}

\section{References}

1. lakovou I, Schmidt T, Bonizzoni E, Ge L, Sangiorgi GM, Stankovic G, Airoldi F, Chieffo A, Montorfano M, Carlino M, et al. Incidence, predictors, and outcome of thrombosis after successful implantation of drug-eluting stents. JAMA. 2005;293(17):2126-30.

2. Kimura T, Morimoto T, Kozuma K, Honda Y, Kume T, Aizawa T, Mitsudo K, Miyazaki S, Yamaguchi T, Hiyoshi E, et al. Comparisons of baseline demographics, clinical presentation, and long-term outcome among patients with early, late, and very late stent thrombosis of sirolimus-eluting stents: observations from the registry of stent thrombosis for review and reevaluation (RESTART). Circulation. 2010;122(1):52-61.

3. Stone GW, Witzenbichler B, Weisz G, Rinaldi MJ, Neumann FJ, Metzger DC, Henry TD, Cox DA, Duffy PL, Mazzaferri E, et al. Platelet reactivity and clinical outcomes after coronary artery implantation of drug-eluting stents (ADAPTDES): a prospective multicentre registry study. Lancet. 2013;382(9892):614-23.

4. Capodanno D, Angiolillo DJ. Platelet monitoring for PCl: which test is the one to choose? Hamostaseologie. 2009;29(4):376-80.

5. Gurbel PA, Becker RC, Mann KG, Steinhubl SR, Michelson AD. Platelet function monitoring in patients with coronary artery disease. J Am Coll Cardiol. 2007;50(19):1822-34.

6. Cayla G, Cuisset T, Silvain J, Leclercq F, Manzo-Silberman S, Saint-Etienne C, Delarche N, Bellemain-Appaix A, Range G, El Mahmoud R, et al. Platelet function monitoring to adjust antiplatelet therapy in elderly patients stented for an acute coronary syndrome (ANTARCTIC): an open-label, blinded-endpoint, randomised controlled superiority trial. Lancet. 2016; 388(10055):2015-22.

7. Collet JP, Cuisset T, Range G, Cayla G, Elhadad S, Pouillot C, Henry P, Motreff $P$, Carrie D, Boueri Z, et al. Bedside monitoring to adjust antiplatelet therapy for coronary stenting. N Engl J Med. 2012;367(22):2100-9.

8. Price MJ, Angiolillo DJ, Teirstein PS, Lillie E, Manoukian SV, Berger PB, Tanguay JF, Cannon CP, Topol EJ. Platelet reactivity and cardiovascular outcomes after percutaneous coronary intervention: a time-dependent analysis of the gauging responsiveness with a VerifyNow P2Y12 assay: impact on thrombosis and safety (GRAVITAS) trial. Circulation. 2011; 124(10):1132-7.

9. Trenk D, Stone GW, Gawaz M, Kastrati A, Angiolillo DJ, Muller U, Richardt G, Jakubowski JA, Neumann FJA. Randomized trial of prasugrel versus clopidogrel in patients with high platelet reactivity on clopidogrel after elective percutaneous coronary intervention with implantation of drug-eluting stents: results of the TRIGGER-PCI (testing platelet reactivity in patients undergoing elective stent placement on Clopidogrel to guide alternative therapy with Prasugrel) study. J Am Coll Cardiol. 2012;59(24):2159-64.

10. Aradi D, Storey RF, Komocsi A, Trenk D, Gulba D, Kiss RG, Husted S, Bonello L, Sibbing D, Collet JP, et al. Expert position paper on the role of platelet function testing in patients undergoing percutaneous coronary intervention. Eur Heart J. 2014;35(4):209-15.

11. Viviani Anselmi C, Briguori C, Roncarati R, Papa L, Visconti G, Focaccio A, De Micco F, Latronico MV, Pagnotta P, Condorelli G. Routine assessment of onclopidogrel platelet reactivity and gene polymorphisms in predicting clinical outcome following drug-eluting stent implantation in patients with stable coronary artery disease. JACC Cardiovasc Interv. 2013;6(11):1166-75.

12. Zhang JJ, Gao XF, Ge Z, Tian NL, Liu ZZ, Lin S, Ye F, Chen SL. High platelet reactivity affects the clinical outcomes of patients undergoing percutaneous coronary intervention. BMC Cardiovasc Disord. 2016;16(1):240.

13. Redfors B, Genereux P, Witzenbichler B, Kirtane AJ, Maehara A, Weisz G, Madhavan MV, McAndrew T, Mehran R, Stone GW. Percutaneous coronary intervention of bifurcation lesions and platelet reactivity. Int J Cardiol. 2018; 250:92-7.

14. Stuckey TD, Kirtane AJ, Brodie BR, Witzenbichler B, Litherland C, Weisz G, Rinaldi MJ, Neumann FJ, Metzger DC, Henry TD, et al. Impact of aspirin and Clopidogrel Hyporesponsiveness in patients treated with drug-eluting stents: 2-year results of a prospective, Multicenter Registry Study. JACC Cardiovasc Interv. 2017;10(16):1607-17.

15. Guan J, Cong Y, Ren J, Zhu Y, Li L, Deng X, Bai J. Comparison between a new platelet count drop method PL-11, light transmission aggregometry, VerifyNow aspirin system and thromboelastography for monitoring shortterm aspirin effects in healthy individuals. Platelets. 2015;26(1):25-30.
16. Thygesen K, Alpert JS, White HD. Joint ESCAAHAWHFTFftRoMI. Universal definition of myocardial infarction. Eur Heart J. 2007;28(20):2525-38.

17. Mehran R, Rao SV, Bhatt DL, Gibson CM, Caixeta A, Eikelboom J, Kaul S, Wiviott SD, Menon V, Nikolsky E, et al. Standardized bleeding definitions for cardiovascular clinical trials: a consensus report from the bleeding academic research consortium. Circulation. 2011;123(23):2736-47.

18. Cutlip DE, Windecker S, Mehran R, Boam A, Cohen DJ, van Es GA, Steg $P G$, Morel MA, Mauri L, Vranckx $P$, et al. Clinical end points in coronary stent trials: a case for standardized definitions. Circulation. 2007;115(17): 2344-51.

19. Ryan TJ, Bauman WB, Kennedy JW, Kereiakes DJ, King SB 3rd, McCallister BD, Smith SC Jr, Ullyot DJ. Guidelines for percutaneous transluminal coronary angioplasty. A report of the American Heart Association/American College of Cardiology Task Force on assessment of diagnostic and therapeutic cardiovascular procedures (committee on percutaneous transluminal coronary angioplasty). Circulation. 1993;88(6):2987-3007.

20. Michelson AD, Bhatt DL. How I use laboratory monitoring of antiplatelet therapy. Blood. 2017;130(6):713-21.

21. Tantry US, Gesheff M, Liu F, Bliden KP, Gurbel PA. Resistance to antiplatelet drugs: what progress has been made? Expert Opin Pharmacother. 2014; 15(17):2553-64.

22. Dezsi DA, Merkely B, Skopal J, Barabas E, Varnai K, Falukozy J, Veress G, Alotti $\mathrm{N}$, Aradi D. Impact of test conditions on ADP-induced platelet function results with the multiplate assay: is further standardization required? J Cardiovasc Pharmacol Ther. 2018;23(2):149-54.

23. Ignjatovic V, Pavlovic S, Miloradovic V, Andjelkovic N, Davidovic G, Djurdjevic P, Stolic R, Iric-Cupic V, Simic I, Ignjatovic VD, et al. Influence of different beta-blockers on platelet aggregation in patients with coronary artery disease on dual antiplatelet therapy. I Cardiovasc Pharmacol Ther. 2016;21(1):44-52.

24. Wallentin L, Becker RC, Budaj A, Cannon CP, Emanuelsson H, Held C, Horrow J, Husted S, James S, Katus H, et al. Ticagrelor versus clopidogrel in patients with acute coronary syndromes. N Engl J Med. 2009;361(11):1045-57.

25. Wiviott SD, Braunwald E, McCabe CH, Montalescot G, Ruzyllo W, Gottlieb S, Neumann FJ, Ardissino D, De Servi S, Murphy SA, et al. Prasugrel versus clopidogrel in patients with acute coronary syndromes. N Engl J Med. 2007; 357(20):2001-15.

26. Becker RC, Bassand JP, Budaj A, Wojdyla DM, James SK, Cornel JH, French J, Held C, Horrow J, Husted S, et al. Bleeding complications with the P2Y12 receptor antagonists clopidogrel and ticagrelor in the PLATelet inhibition and patient Outcomes (PLATO) trial. Eur Heart J. 2011;32(23):2933-44.

27. Cuisset T, Deharo P, Quilici J, Johnson TW, Deffarges S, Bassez C, Bonnet G, Fourcade L, Mouret JP, Lambert M, et al. Benefit of switching dual antiplatelet therapy after acute coronary syndrome: the TOPIC (timing of platelet inhibition after acute coronary syndrome) randomized study. Eur Heart J. 2017;38(41):3070-8.

28. Zocca P, van der Heijden LC, Kok MM, Lowik MM, Hartmann M, Stoel MG, Louwerenburg JW, de Man F, Linssen GCM, Knottnerus IL, et al. Clopidogrel or ticagrelor in acute coronary syndrome patients treated with newergeneration drug-eluting stents: CHANGE DAPT. Eurolntervention. 2017; 13(10):1168-76.

29. Lordkipanidze M, Pharand C, Nguyen TA, Schampaert E, Palisaitis DA, Diodati JG. Comparison of four tests to assess inhibition of platelet function by clopidogrel in stable coronary artery disease patients. Eur Heart J. 2008; 29(23):2877-85.

30. Lemesle G, Landel JB, Bauters A, Delhaye C, Bonello L, Sudre A, Susen S, Bauters $C$, Lablanche JM. Poor agreement between light transmission aggregometry, verify now P2Y(1)(2) and vasodilatator-stimulated phosphoprotein for clopidogrel low-response assessment: a potential explanation of negative results of recent randomized trials. Platelets. 2014; 25(7):499-505

31. Franchi F, Rollini F, Cho JR, Ferrante E, Angiolillo DJ. Platelet function testing in contemporary clinical and interventional practice. Curr Treat Options Cardiovasc Med. 2014;16(5):300

32. Paniccia R, Priora R, Liotta AA, Abbate R. Platelet function tests: a comparative review. Vasc Health Risk Manag. 2015;11:133-48,

33. Sibbing D, Aradi D, Jacobshagen C, Gross L, Trenk D, Geisler T, Orban M, Hadamitzky M, Merkely B, Kiss RG, et al. Guided de-escalation of antiplatelet treatment in patients with acute coronary syndrome undergoing percutaneous coronary intervention (TROPICAL-ACS): a randomised, openlabel, multicentre trial. Lancet. 2017;390(10104):1747-57. 
34. Tang Y-D, Wang W, Yang M, Zhang K, Chen J, Qiao S, Yan H, Wu Y, Huang X, Xu B, et al. Randomized comparisons of double-dose Clopidogrel or adjunctive Cilostazol versus standard dual Anti-platelet in patients with high post-treatment platelet reactivity: results of the CREATIVE trial (Clopidogrel response evaluation and AnTi-platelet InterVEntion in high thrombotic risk PCI patients). Circulation. 2018. PMID:29420189. https://doi.org/10.1161/ CIRCULATIONAHA.117.030190.

35. Snoep JD, Hovens MM, Eikenboom JC, van der Bom JG, Huisman MV. Association of laboratory-defined aspirin resistance with a higher risk of recurrent cardiovascular events: a systematic review and meta-analysis. Arch Intern Med. 2007;167(15):1593-9.

36. Bhatt DL, Grosser T, Dong JF, Logan D, Jeske W, Angiolillo DJ, Frelinger AL 3rd, Lei L, Liang J, Moore JE, et al. Enteric coating and aspirin nonresponsiveness in patients with type 2 diabetes mellitus. J Am Coll Cardiol. 2017;69(6):603-12.

37. Grosser T, Fries S, Lawson JA, Kapoor SC, Grant GR, FitzGerald GA. Drug resistance and pseudoresistance: an unintended consequence of enteric coating aspirin. Circulation. 2013;127(3):377-85.

38. Patrono C. The multifaceted clinical readouts of platelet inhibition by lowdose aspirin. J Am Coll Cardiol. 2015;66(1):74-85.

39. Kim MH, Choi SY, An SY, Serebruany V. Validation of three platelet function tests for bleeding risk stratification during dual antiplatelet therapy following coronary interventions. Clin Cardiol. 2016;39(7):385-90.

Ready to submit your research? Choose BMC and benefit from:

- fast, convenient online submission

- thorough peer review by experienced researchers in your field

- rapid publication on acceptance

- support for research data, including large and complex data types

- gold Open Access which fosters wider collaboration and increased citations

- maximum visibility for your research: over $100 \mathrm{M}$ website views per year

At BMC, research is always in progress.

Learn more biomedcentral.com/submissions 